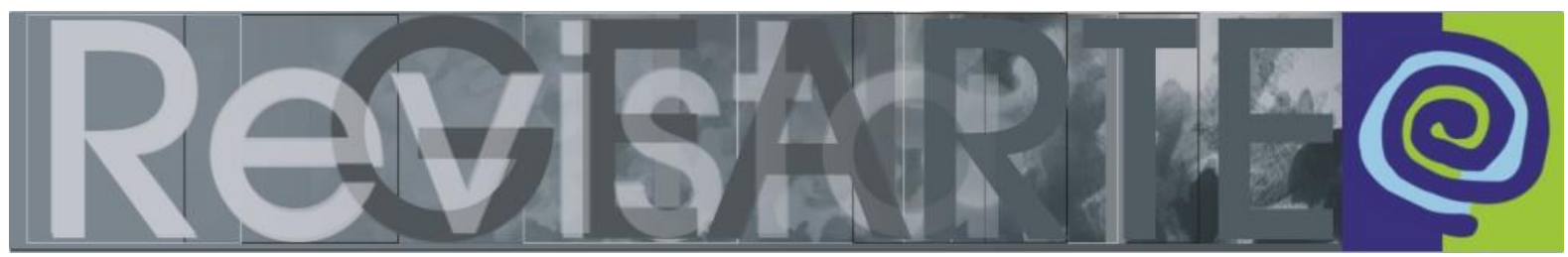

e-ISSN 2357-9854

\title{
Retomando - A arte possibilita ao ser humano repensar suas certezas e reinventar o seu cotidiano - a partir da ideia: Incerteza Viva
}

\author{
Fernando Antônio Gonçalves de Azevedo (Universidade Federal \\ Rural de Pernambuco - UFRPE, Recife/ PE, Brasil)
}

\begin{abstract}
RESUMO - Retomando - A arte possibilita ao ser humano repensar suas certezas e reinventar o seu cotidiano - a partir da ideia: Incerteza Viva - Retomo e reabro o texto que escrevi desafiado pela instalação The Chain, do fotógrafo Chien Chi Chang, exposta na 25a Bienal de São Paulo em 2002. Essa experiência levou-me a compreender que a arte possibilita ao ser humano repensar suas certezas e reinventar o seu cotidiano. O que se casa com a ideia de Incerteza Viva, tema da Bienal de São Paulo em 2016. Nas duas experiências tomei como referência a Abordagem Triangular, sendo que na primeira tentativa a compreendia como metodologia. Hoje, entretanto, compreendo-a como teoria de interpretação do universo das Artes e Culturas Visuais. Mudança substancial, que me obriga não apenas ao gesto de retomar e reabrir a experiência, mas, também, de dizer que a Abordagem Triangular possibilita articular dialogicamente o campo de conhecimento da Arte com a Filosofia e a Ciência, pois é uma teoria marcada pela ideia de Incerteza.
\end{abstract}

PALAVRAS-CHAVE

Abordagem Triangular. Incerteza Viva. Leitura de Imagem.

ABSTRACT - Resuming - Art makes possible to human beings rethink their certainties and reinventing their everyday life - based on the idea: Uncertainty Alive - I resume and reopen the text that I wrote challenged by the installation The Chain of the photographer Chien Chi Chang, exposed in the 25th São Paulo Biennial in 2002. That experience led me to understand that art allows the human being to rethink their certainties and reinvent their life. This combines with the idea of Uncertainty Alive, theme of the São Paulo Biennial in 2016. In both experiences, I took as a reference the Triangular Approach, in the first attempt, I understood it as a methodology. Today, however, I understand it as a theory of interpretation of the universe of arts and visual cultures. Substantial change, which requires me not only to the gesture of resume and reopen the experience, but, also, to say that the Triangular Approach makes it possible, to articulate dialogically the field of knowledge of Art with Philosophy and Science, because it is a theory that is marked by the idea of Uncertainty

KEYWORDS

Triangular Approach. Uncertainty Alive. Image Reading.

As artes sempre trabalharam com o desconhecido. Historicamente, a arte insistiu em um vocabulário que levasse em conta a ficção e que qualificasse a incerteza. A informação se perde e a dúvida persiste, mas a arte pode moderar esses paradoxos ao operar fora dos sistemas padrão, escalas e normas, pela introdução de modelos e medidas alternativas. $A$ arte se vale da incapacidade dos meios existentes para descrever o sistema de que somos parte - ela aponta para a sua desordem. O mais importante: a arte pode fazer isso porque junta pensar e fazer, reflexão e ação. $A$ arte está fundada na imaginação, $e$

AZEVEDO, Fernando Antônio Gonçalves de. Retomando - A arte possibilita ao ser humano 
somente através da imaginação seremos capazes de conceber outras narrativas para nosso passado e novos caminhos para o futuro (Jochen Volz).

\section{Retomo e reabro...}

Desafiado pelo tema Incerteza Viva, da 32ª Bienal de São Paulo-2016, decidi retomar e reabrir um texto que havia escrito, desafiado por sua vez, pela 25a Bienal de São Paulo (2002), que teve como tema Iconografias Metropolitanas. Nesse caso, refiro-me, especialmente, à instalação The Chain do fotógrafo Chien Chi Chang, cuja tentativa de criar uma interpretação pela via da teoria, nomeada de Abordagem Triangular possibilitou uma reflexão sobre a arte como um campo de conhecimento muito próximo da filosofia, pois uma e outra provocam o questionamento, a crítica e a imaginação, como diz, na epígrafe sobre a arte Jochen Volz, curador da $32^{a}$ Bienal de São Paulo. Ambas - a arte e a filosofia - por essas razões, nos ajudam a colocar em questão nossas pobres certezas.

Nos idos de 2002, intuitivamente, via a relação entre a arte e a filosofia como muito promissora. Mas, precisava de ancoragem, o que me levou a buscar o famoso ensaio de Walter Benjamin (1892-1940) - A obra de arte na era de sua reprodutibilidade técnica (1996) - texto que recebi de presente do professor Jomard Muniz de Brito, um filósofo pernambucano que sabe bem relacionar arte e filosofia. Benjamin, não podemos esquecer, foi filiado à Teoria Crítica, e esse ensaio em particular é, até nossos dias, muito importante para os estudos da imagem, tendo me ajudado a compreender as transformações provocadas pela fotografia no estatuto das Belas Artes.

Hoje, seria impossível não acrescentar à relação dialogal entre a arte e a filosofia, a ciência, pela via da física, mais precisamente, relacionada ao Princípio da Incerteza, apresentado à comunidade científica em 1927, pelo físico alemão Werner Heisenberg (1901-1976).

É necessário dizer que em 2002 compreendia a Abordagem Triangular como um sistema metodológico que articulava as ações Ler-Contextualizar-Fazer, tornando possível a leitura da imagem. Hoje, compreendo-a como uma teoria de interpretação da imagem. Transformação que ocorreu a partir da pesquisa desenvolvida no Curso 
de Doutorado em Educação do Centro de Educação da Universidade Federal de Pernambuco - CE/UFPE, sob a orientação da Professora Dra Clarissa Martins de Araújo e a coorientação da Professora Drª Analice Dutra Pillar, da Faculdade de Educação da UFRGS.

O foco da pesquisa foi analisar os discursos - memórias da práxis arteducativa - de três arte/educadores ${ }^{1}$ registrados em uma materialidade visual-verbal, nomeada de caderno de bordo. Materialidade híbrida, que junta o diário etnográfico com o livro de artista, enfatizando, do primeiro, o registro da memória e do segundo, o discurso visual-verbal.

Para tanto, busquei estudar a teoria da Análise de Discurso elaborada, principalmente, por Eni Orlandi (2013), autora que esclarece: "A análise de discurso não é uma ciência exata. É uma ciência da interpretação". Destaco, a seguir, outro importante esclarecimento, também, com ancoragem no pensamento de Orlandi:

[...] não há um sistema de signos só, mas muitos. Porque há muitos modos de significar e a matéria significante tem plasticidade, é plural. Como os sentidos não são indiferentes à matéria significante, a relação do homem com os sentidos se exerce em diferentes materialidades, em processos de significação diversos: pintura, imagem, música, escultura, escrita, etc. (ORLANDI, 2007, p. 12).

Ao estudar o trabalho da coreógrafa e bailarina alemã Pina Bausch (19402009), Orlandi em seu livro Análise de Discurso: Sujeito, Sentido, Ideologia (2012) acrescenta a Dança, como mais uma das materialidades possíveis de serem analisadas por meio da Análise de Discurso. Significando, claramente, que as diferentes linguagens artísticas produzem diferentes materialidades discursivas. Isso, é claro, porque os sentidos de nossos discursos - sejam eles por meio da palavra, da imagem ou do gesto - não são precisos e transparentes; eles requerem a Análise de Discurso como ciência de interpretação e, por isso, dependem do contexto em que se

1 Maria de Fátima Ribeiro Soares, com o caderno de bordo "A Poesia Ocupando a Vida, Invadindo a Escola"; Misael José de Santana, com o caderno de Bordo "AH! Se Eu Tivesse Dinheiro: museus, espaços informais de acesso e compreensão da arte; e Virgínia Marques, com o caderno de bordo "Descobrindo Lugares de Ser". Os três arte/educadores atuam em escolas públicas estaduais de Pernambuco. A tese foi publicada no livro: A Abordagem Triangular no Ensino das Artes como Teoria e a Pesquisa como Experiência Criadora, pelo Sesc, em 2016. 
diz algo por meio da palavra, em que se diz algo por meio da imagem e em que se diz algo por meio do gesto.

Abro um parêntese para enfatizar: recordo e não posso deixar de trazer à tona que a importância do contexto no processo de leitura da imagem, naquele momento histórico, isto é, por volta dos anos 2000, já era destaque nos textos de Ana Mae Barbosa. Um bom exemplo é seu livro Tópicos utópicos (1998). Até em palestras anteriores a essa época, a arte/educadora apresentava leituras interpretativas de imagens, enfatizando a relevância do contexto. Essa ênfase ao contexto foi decisiva para a leitura que tentei produzir sobre a instalação The chain, fato que desencadeou a primeira versão do texto - A arte possibilita ao ser humano repensar suas certezas e reinventar seu cotidiano (2009) -, que agora retomo e reabro, impactado pela ideia de Incerteza Viva.

Foi, portanto, a partir dos estudos sobre Análise de Discurso, elaborados por Orlandi e ditos de diferentes maneiras em sua produção teórica, que fui interpretando a Abordagem Triangular, não apenas como um sistema metodológico, mas, sobretudo, como uma teoria de interpretação do universo das Artes e Culturas Visuais. Ademais, essa pesquisa me fez compreender a Abordagem Triangular como uma teoria de tal modo aberta, que convida o arte/educador a rearranjá-la ao seu modo, considerando o seu próprio contexto histórico, social e cultural e, também, os dos estudantes, pois é uma teoria fortemente identificada, não apenas, a uma interpretação do pensamento pós-moderno, mas também, com as questões póscoloniais.

Cabe uma explicação: a compreensão do que é o pensamento pós-moderno é divergente. Aqui, refere-se a um entendimento de história não linear, pois, é um pensamento marcado pelo desencanto com relação a noção de progresso. $E$, ao contrário do modernismo, considera o passado. Além disso, não se assume como verdade absoluta. Em arte, sobretudo, rejeita a originalidade como valor maior, sendo, também, avessa aos dogmas e às hierarquias (BARBOSA, 2007; EFLAND, 2005).

Ao identificar-se com as questões pós-coloniais, a Abordagem Triangular enfrenta, pois, a ferida da desigualdade entre diferentes sujeitos sociais e culturais, 
ferida herdada do processo de colonização, que estabeleceu entre esses diferentes sujeitos culturais, uma relação hierárquica baseada no mandar e na obedecer, ou seja, distinguindo quem tem voz ativa na sociedade - os sujeitos de direito - e os que obedecem, pois, suas vozes pouco significam na cena social. Em linguagem freireana: os primeiros (os mandantes) dizem a palavra, pois têm autoridade herdada e reconhecida, enquanto os outros (os obedientes) são condenados à cultura do silêncio (FREIRE, 2005).

A Abordagem Triangular, vista pela perspectiva pós-colonial, suscita no campo mais amplo da Arte/Educação, e de maneira mais especifica no campo do ensino e da aprendizagem em Artes e Culturas Visuais, uma concepção de epistemologia que trabalha pela descolonização do conhecimento, compreendendo que todos os sujeitos sociais e culturais têm direito a usufruir da arte e o melhor meio para que isso aconteça, com relação às Artes Visuais, é a leitura da imagem. Isso porque ela nos encaminha para o diálogo entre diversas narrativas culturais - o que leva a leituras mais amplas e complexas de mundo. Lembro, junto com Analice Dutra Pillar (2011, p. 296) que: "No contexto brasileiro, a denominação leitura de imagens passou a fazer parte do ensino de arte na escola, de modo sistemático, a partir do final da década de 1980 com a Abordagem Triangular".

Retomo e reabro, pois, a ideia: a arte possibilita ao ser humano repensar suas certezas e reinventar seu cotidiano, profundamente tomado pelo contexto em que vivemos. Busco, a seguir, as palavras de Volz $(2016$, p. 23) para dizer sobre o que chamo de contexto em que vivemos:

\begin{abstract}
Mesmo que as predições de eventos futuros em nosso planeta tenham contradições, pensadores de todos os campos clamam por ação imediata. Exigem que se eleve a consciência coletiva em todo o globo para os desafios que nossas sociedades enfrentam neste momento. Mas há um longo percurso até que os currículos escolares, as pautas da mídia e os programas políticos abracem efetivamente essas questões como uma causa comum (VOLZ, 2016, on-line).
\end{abstract}

Por um lado, o contexto do tempo em que vivemos, influenciado por profundas incertezas, conforme Volz (2016), pode nos levar a inventar saídas, produzir alternativas, gerar soluções divergentes, ver de maneira diferenciada a realidade, para atuar no mundo de um jeito plural. Por outro lado, ao ressaltar sobre a produção do 
conhecimento da ciência pós-moderna, Boaventura de Souza Santos em sua provocativa obra Um discurso sobre as ciências menciona que:

[...] o fundamento do estatuto privilegiado da racionalidade científica não é, em si mesmo cientifico. [...] A ciência moderna produz conhecimentos e desconhecimentos. Se faz do cientista um ignorante especializado faz do cidadão comum um ignorante generalizado. [Enquanto] a ciência pósmoderna sabe que nenhuma forma de conhecimento é, em si mesma, racional; só a configuração de todas elas é racional. Tenta, pois, dialogar com outras formas de conhecimento deixando-se penetrar por elas. A mais importante de todas é o conhecimento do senso comum, o conhecimento vulgar e prático com que no quotidiano orientamos as nossas ações e damos sentido à nossa vida (SANTOS, 2010, p. 55).

A ideia de Santos é significativa e casa com a ideia de Volz (não é por acaso, portanto, que Santos tenha escrito para o catálogo da 32ª Bienal de São Paulo), pois o discurso da Bienal em destaque é profundamente influenciado pelos trânsitos entre o pensamento moderno e o pós-moderno - entre a certeza e a incerteza -, desafiando-nos a refletir sobre uma concepção de arte, que dialoga com a filosofia e com a ciência, na perspectiva de inventar outras possibilidades de Ser (ser humano) e de Viver (no mundo). O que me leva a citar, novamente, Volz (2016, p. 23): "a arte se vale da incapacidade dos meios existentes para descrever o sistema de que somos parte - ela aponta para a sua desordem. O mais importante: a arte pode fazer isso porque junta pensar e fazer, reflexão e ação."

A sistematização da Abordagem Triangular, no contexto complexo da transição entre o pensamento modernista e o pós-modernista, imprimiu a essa teoria uma abertura para o diálogo com os campos da filosofia e da ciência, indicando que refletir sobre a leitura da imagem em um mundo marcado pela incerteza, requer do arte/educador, conforme Barbosa, compreender que:

Enquanto no modernismo se privilegiava, dentre as funções criadoras, a originalidade preservando o estudante do contato com a obra de arte, a pósmodernidade vem enfatizando a elaboração, dentre os outros processos mentais envolvidos na criatividade (BARBOSA,1991, p. 89).

Ana Mae Barbosa, nesse sentido, é enfática ao propor o gesto de elaborar, no sentido de compor, construir, criar (talvez seja melhor dizer: recriar) no processo de leitura da imagem. Compreendo esse gesto, avizinhado da noção de subjetivação, pois ao ler as imagens da arte e/ou da cultura visual, estamos de alguma maneira nos 
constituindo enquanto sujeitos. Estamos tentando, no mínimo, dizer de nós mesmos, o que, de certo modo, vai na direção da reflexão colhida do pensamento do crítico de arte francês Nicolas Bourriaud, em Pós-produção: como a arte reprograma o mundo contemporâneo, ao observar que:

\begin{abstract}
Quando Marcel Duchamp expõe um objeto manufaturado (um porta-garrafas, um urinol, uma pá de neve...) como obra do espírito, ele desloca a problemática do processo criativo, colocando a ênfase não em alguma habilidade manual, e sim no olhar do artista sobre o objeto. Ele afirma que o ato de escolher é suficiente para fundar a operação artística, tal como o ato de fabricar, pintar ou esculpir: "atribuir uma nova ideia" a um objeto é, em si, uma produção. Desse modo, Duchamp completa a definição do termo: criar é inserir um objeto num novo enredo, considerá-lo como um personagem numa narrativa (BOURRIAUD, 2009, p. 22).
\end{abstract}

A elaboração, enquanto processo mental envolvido no gesto criativo de ler a imagem, desloca a habilidade manual para o processo de interpretação da imagem, como uma maneira de reinventá-la e reinventar-se, uma vez que, o nosso dizer sobre a imagem é possibilidade de recriação, tal como afirma Bourriaud (2009, p. 22) ancorado em Duchamp, já que " $[\ldots]$ o ato de escolher é suficiente para fundar a operação artística [...]" , e complementa: "[...] "atribuir uma nova ideia" a um objeto é, em si, uma produção.".

Assim, surge a questão: será o gesto de recriação o mais aproximado ao Princípio da Incerteza? Mas não devemos esquecer: nossos dizeres (sobre a arte e tudo mais) jamais serão definitivos e completos, no máximo, os admitimos como contextuais ângulos de visão - mais próximos das incertezas (vivas) do que das certezas (mortas). Apresento, a seguir, a sequência, sujeito ao acaso.

\title{
Sujeito ao acaso
}

Em minha primeira visita à $32^{\mathrm{a}}$ Bienal de São Paulo, por acaso entrei pelo portão principal do prédio, fato que me levou a viver uma experiência estética muito significativa, por meio da instalação Ágora: OcaTaperaTerreiro (Oca, doravante) do artista Bené Fonteles. Aviso, desde já, que neste pequeno ensaio me deterei nessa instalação. 
Início destacando que na Oca havia, escrito no chão, o seguinte avisoprovocação: "Isto aqui não é arte". Como que evocando o sentido de Ágora para os gregos: lugar de juntar pessoas para pensar, para refletir e agir, realizar diálogos...

No entanto, a Oca é arte porque provoca pensar, desestabiliza o leitor, forçando-o a refletir sobre o próprio tema da $32^{\underline{a}}$ Bienal de São Paulo: Incerteza Viva. Tirando-nos o chão. Pondo em xeque as nossas pobres certezas. Uma delas, talvez a mais forte, seja o fato de Bené Fonteles, por meio do seu discurso-instalação, questionar a sacralização da arte, ou seja, uma certa concepção de arte identificada ao cânon ocidental de cultura, caracterizado pela supremacia da cultura branca, europeia e masculina. Ou seja, o artista, por meio da Oca, instaura um processo de descolonização.

Acessar a Oca, é como ultrapassar um portal, porque somos introduzidos em uma dimensão da memória ligada à nossa formação cultural e à nossa história de povo colonizado. Isso exige uma elaboração que não termina ali; na verdade ali se inicia. A Oca é a entrada para a delicada e desafiadora curadoria de Volz, que ultrapassa a noção de pura contemplação, pois é um posicionamento político sobre a nossa colonização. Contextualiza a colonização por meio de uma epistemologia descolonizadora. E aqui é bom lembrar Ana Mae Barbosa (1998, p. 38) em Tópicos utópicos: "contextualizar é estabelecer relações."

Assim, ao colocar em dúvida a visão eurocêntrica de conceber e lidar com o universo da arte, o artista interroga, também, o processo de elaboração da "obra de arte" e o processo de sua leitura. A Oca, enfim, põe em xeque o próprio sistema da arte. E talvez seja essa a interpretação mais plausível que podemos atribuir à ideia de Incerteza Viva: dessacralizar a arte, com base em uma reflexão interdisciplinar, intercultural e interterritorial.

A Oca, vista como simbolismo do processo de dessacralização da arte, aponta, pois, para uma concepção de epistemologia descolonizadora (AZEVEDO, 2015), além de ser um convite ao gesto de problematizar, como outros trabalhos na $32^{\text {a }}$ Bienal de São Paulo. Cito um, que não me deterei, pois esse merece um ensaio próprio, mas 
que, também, muito me desafio por partir de uma epistemologia descolonizadora: Projeto desejos de Grada Kilomba².

Ao apresentar a epistemologia descolonizadora operando no campo da arte, de maneira interdisciplinar, intercultural e interterritorial, é urgente dizer: a epistemologia colonizadora é aquela que estabelece, na sociedade em que vivemos, quem são os detentores do discurso e quem deve ter sonegado o seu direito à palavra. É, pois, a que se sustenta fabricando a discórdia entre os diferentes.

Por isso, talvez, nos pejis (local sagrado onde se expõem imagens e oferendas na cultura religiosa africana), o artista entrona ícones da cultura brasileira, tais como: Paulo Freire, Nise da Silveira e João Guimarães Rosa. O primeiro, por meio da obra Paulo Freire: uma biobibliografia (GADOTTI, 1996); a segunda, por meio de Nise da Silveira: caminhos de uma psiquiatra rebelde (MELLO, 2015) e o terceiro, por ter sido o escritor da bela relação de amor entre Diadorim e Riobaldo, em Grande Sertão: Veredas (ROSA, 2006). Sobre cada um desses ícones, o artista parece enaltecer o gesto rebelde de dizer não às certezas. Freire, em seu trabalho por uma educação libertadora, Dra ${ }^{\text {- }}$ Nise, por uma psiquiatria rebelde e Guimarães Rosa, pelo gesto poético-filosófico libertador.

Destaco em primeiro lugar a $\mathrm{Dr}^{\mathrm{a}}$ - Nise da Silveira, como uma espécie de homenagem à Dona Noemia Varela, porque foi ela quem me apresentou o pensamento de Nise da Silveira. Elas foram amigas e, durante os anos em que morou no Rio de Janeiro, Dona Noemia frequentou o Grupo de Estudos Carl Gustav Jung, aprofundando suas investigações sobre a relação da arte com a psicologia jungiana. O texto em destaque a seguir foi colhido nesse livro, que teve o prefácio escrito pelo professor Marco Lucchesi para a obra de Mello:

A rebelde. A forte. A que soube dizer não. E o rosto, que era um sol. E as
mãos, como que pintadas por El Greco, regiam uma orquestra invisível de
princípios. Mas ao mesmo tempo sofria terrivelmente com a Farra do Boi e
com os atos de violência praticados contra as crianças e os animais. Por eles,
brigava até contra Spinoza - filósofo de sua predileção. Porque era uma das
melhores amigas de Francisco de Assis, cujo respeito pelo ser humano, pelo
ser cão e pelo ser gato (de modo especial) deixou comovido mais de um índio

2 Sugiro, para quem se interessar, a entrevista concedida pela artista à psicanalista Suely Rolnik, disponível em: <http://brasileiros.com.br/2016/09/o-conhecimento-e-colonizacao/>. 
xavante, a ponto de receber deles o título de Cacica da Natureza! (MELLO, 2015, p. 7).

De Paulo Freire (2005, p. 93), ressalto um trecho de Pedagogia do Oprimido: "Como posso dialogar, se me fecho à contribuição dos outros, que jamais reconheço, e até me sinto ofendido com ela?". Em Guimarães Rosa (2006, p. 80), colhi o trecho a seguir de Grande Sertões: Veredas: "Digo: o real não está na saída nem na chegada: ele se dispõe para a gente é no meio da travessia."

E, no meio da travessia deste pequeno ensaio, digo: a instalação em análise é arte (sem dúvida? Jamais). É arte, especialmente no contexto em que o próprio tema da Bienal nos convida a pensar, isto é, a partir de uma visão INTERdisciplinar, INTERcultural, INTERterritorial de conhecimento - apoiada em uma concepção epistemológica descolonizadora - pois a ideia de Incerteza Viva é um tema ancorado na física - não podemos esquecer esse fato. Sendo assim, exige uma relação INTER.

Por tais razões, o próprio tema da Bienal de São Paulo de 2016, juntamente com seu discurso curatorial, colocam o desafio de ler as imagens, estabelecendo com elas relações INTER. Para tanto, é necessária uma ressalva, sobre os sentidos da expressão Incerteza Viva, buscada no pensamento de Volz. Diz ele:

\begin{abstract}
Embora esteja relacionada à palavra crise, não é equivalente. Incerteza é, sobretudo, uma condição psicológica ligada a processos individuais e coletivos de decisão, descrevendo o entendimento e o não entendimento em uma dada situação. INCERTEZA VIVA é sentida em toda parte. É uma condição que se infiltra em nossas cabeças, nossos corpos, nas ruas, no mercado, na floresta ou nos campos. É contagiante, gera imagens, sons, cheiros, instabilidade e também entusiasmo e curiosidade. Ela pode ser vinculada a realidades sociais e mentais, a métodos artísticos, à epistemologia e a uma imaginação rebelde (VOLZ, 2016, p. 24).
\end{abstract}

A próxima sequência refere-se ao Princípio da Incerteza no contexto da história.

\title{
O Princípio da Incerteza muda o rumo da história...
}

A sistematização do Princípio da Incerteza por Heisenberg, em 1927, inevitavelmente muda os rumos da história, não apenas do campo da física, mas, também, da própria ciência, atingindo os campos da arte e o da filosofia. E de modo muito especial, a arte, pois como afirma Volz (2016, p. 24): "Diferentemente do que 
acontece em outros campos de pesquisa, a incerteza na arte aponta para a criação, levando em conta a ambiguidade e a contradição".

Colocando em questão nossas certezas e convicções, estamos, a partir de então, submetidos ao Princípio da Incerteza, sujeitados ao acaso, à especulação, ao acontecimento, ao improviso, pois tal princípio gera possibilidades de narrativas diversas e sempre abertas, sempre se refazendo. O Princípio da Incerteza é contrário à existência de um ponto final.

Esse princípio, ao quebrar a linearidade da história, põe nossas certezas e convicções sob suspeita. Assim, nossas relações com a Vida, passaram a ser profundamente sinalizadas por tal princípio, mesmo que não queiramos, pois rompeuse a certeza e a convicção na ideia de progresso. Pensadores de todos os campos de conhecimento passaram a questionar as grandes narrativas modernistas, que associavam a ideia de progresso ao desenvolvimento (linear) da ciência, e essa a uma vida humana plena e segura. Parecendo afirmar a ciência moderna como uma verdade que levaria o ser humano a uma vida sem contradições e limites, como enfatiza Santos (2010) na sequência intitulada retomo e reabro.

Santos, em seu ensaio $A$ incerteza entre o medo e a esperança, escrito para o catálogo da Bienal São Paulo de 2016, identifica a visão de progresso da ciência moderna com a modernidade eurocêntrica, ressaltando a incerteza do conhecimento. Nesse ensaio ele enfatiza:

Vivemos, [...] uma época da modernidade eurocêntrica, que atribui total prioridade ao conhecimento científico a às práticas diretamente derivadas dele: as tecnologias. Isso significa que a distribuição epistemológica e vivencial do medo e da esperança é definida por parâmetros que tendem a beneficiar os grupos sociais que têm mais acesso ao conhecimento científico e à tecnologia (SANTOS, 2016, p. 39).

O que me encoraja a retomar um outro fragmento de Um discurso sobre as ciências, ou seja, quando o cientista social português ressalta:

A incerteza do conhecimento, que a ciência moderna sempre viu como limitação técnica destinada a sucessivas superações, transforma-se na chave do entendimento de um mundo que mais do que controlado tem de ser contemplado. Não se trata do espanto medieval perante uma realidade hostil possuída do sopro da divindade, mas antes da prudência perante um mundo que, apesar de domesticado, nos mostra cada dia a precariedade do sentido 
da nossa vida por mais segura que esteja ao nível da sobrevivência. (SANTOS, 2010, p. 54).

Entre o medo e a esperança, pois, questiono as narrativas modernistas alimentados pelo Princípio da Incerteza, lembrando que essas provocaram uma ida ao pensamento de Friedrich Nietzsche, e em minhas buscas encontrei o precioso aforismo 630, da obra Humano, demasiado humano. Nesse, Nietzsche afirma:

\begin{abstract}
Convicção é a crença de estar, em algum ponto do conhecimento, de posse da verdade absoluta. Esta crença pressupõe, então, que existam verdades absolutas; e, igualmente, que tenham sido achados os métodos perfeitos para alcançá-las; por fim, que todo aquele que tem convicções se utilize desses métodos perfeitos. Todas as três asserções demonstram de imediato que o homem das convicções não é o do pensamento científico; ele se encontra na idade da inocência teórica e é uma criança, por mais adulto que seja em outros aspectos. [...]. Não foi o conflito de opiniões que tornou a história tão violenta, mas o conflito da fé nas opiniões, ou seja, das convicções (NIETZSCHE, 2005, p. 266).
\end{abstract}

Ao provocar o questionamento das convicções e das crenças, o Princípio da Incerteza impõe ao ser humano colocar sob suspeita as pequenas e grandes certezas que alimentam o imaginário da vida e suas dimensões. E assim, o campo da arte e o sistema que o rege também precisam ser questionados.

\title{
O Sistema da Arte em questão...
}

Uma das certezas em arte, talvez a mais justificada, traduz-se na autoridade que algumas pessoas têm de dizer o que pensam sobre uma obra ou um objeto de arte. Autoridade que raramente é contestada, pois esse pensar representa, antes, e acima de tudo, aquilo que é acordado pelo grupo de poder instituído na sociedade: artistas, críticos de arte, historiadores da arte e curadores - é, pois, o discurso competente dos que constituem o sistema da arte, mesmo que, individualmente, as pessoas que têm voz ativa, concedida por esse sistema, não assumam o tom autoritário em seus discursos. Eles representam, por meio da legitimação de um poder outorgado e raramente questionado, o discurso dos que são autorizados a dizer o que é arte e o que não é arte, o que tem qualidade e o que não tem. Tais grupos, além disso, muitas vezes, possuem ligações com o mercado, pautando seus discursos pelo valor econômico de obras e objetos de arte, muito mais do que pelo valor histórico e cultural. 
A analista de discurso Eni Orlandi, nesse sentido, ao tomar o pensamento de Pierre Bourdieu, nos ajuda a contextualizar o problema do discurso de autoridade, no campo do ensino e da aprendizagem das Artes e Culturas Visuais, ao analisar:

[...] há uma correspondência entre a distribuição do capital cultural e do capital econômico e do poder entre as diferentes classes: a posse dos bens culturais, e que uma formação social seleciona como dignos de serem possuidores, supõe a posse prévia de um código que permite decifrá-lo. E assim instala-se uma circularidade: só os possui os que já tem condições de possuí-lo. Por outro lado, a escola tem uma função de dissimulação: apresenta hierarquias sociais e a reprodução dessas como se estivessem baseadas na hierarquia de 'dons', méritos ou competências e não como hierarquia fundada na afirmação brutal das relações de força. Convertem hierarquias sociais em hierarquias escolares e com isso legitimam a perpetuação da ordem social (ORLANDI, 2011, p. 22).

A autoridade de dizer sobre o universo da arte, de um modo geral e de uma maneira mais específica sobre as Artes e Culturas Visuais, distinguindo o discurso de quem possui tal poder, do discurso de quem não o possui, conforme Bourdieu (2007) na obra A Distinção: crítica social do julgamento, obedece à hierarquia, que determina na sociedade quem são os detentores da palavra e quem são os silenciados. Daí sua crítica ao discurso pedagógico, que reproduz, na escola, o sistema de distinção: uns podem dizer o que pensam sobre a arte (e sobre outros temas...) e os outros são calados. A partir dessa lógica, os silenciados estão condenados ao silêncio, porque, também, não têm acesso ao "sofisticado" universo da arte, enquanto os outros tiveram acesso a um processo de iniciação, compreendidos, por isso, como aqueles reconhecidos e legitimados a dizerem o que pensam sobre a arte.

Eis o grande desafio do arte/educador na contemporaneidade, alimentado por uma epistemologia descolonizadora, busca possibilitar o repensar as certezas e o reinventar o cotidiano por meio da leitura da imagem.

\section{O sempre difícil ponto final...}

Iniciar um texto é uma aventura, concluir é muito difícil, até, porque nenhuma reflexão transformada em texto tem ponto final. Para (quase) concluir este ensaio busquei ancoragem em Jorge Larrosa (2015). Refiro-me à Pedagogia Profana: danças, piruetas e mascaradas. Na última parte deste livro - Figuras do Porvir Larrosa faz um elogio ao riso na pedagogia. 
Como se pode perceber, o próprio título da obra em diálogo com a reflexão sobre o riso é uma possibilidade de encontro com a ideia de Incerteza Viva e o campo mais amplo da Arte/Educação, uma vez que Larrosa diz:

O riso destrói as certezas. E especialmente aquela certeza que constitui a consciência enclausurada: a certeza de si. Mas só na perda da certeza, no permanente questionamento da certeza, na distância irônica da certeza, está a possibilidade do devir. $O$ riso permite que o espirito alce voo sobre si mesmo. O chapéu de guizos tem asas (LARROSA, 2015, p. 181).

Digo, pois, junto com Larrosa, que o gesto de rir, que é ambíguo e perigoso, é o mesmo da arte vestida com seu chapéu de guizos, indicando que é possível o voo. E para alçar voos, não esquecer a autoironia, isto é, segundo Larrosa (2015), um componente da própria consciência, o que significa: nunca esquecermos de duvidar de nossas certezas.

Retomo a ideia geradora deste texto, para dizer: a arte, a filosofia e a ciência possibilitam ao ser humano repensar suas certezas e reinventar o seu cotidiano. Lancemo-nos, pois, rindo, ao perigo - gerador de possibilidades - de lidar com as Artes e Culturas Visuais por meio da Abordagem Triangular, compreendida como teoria de interpretação do universo das imagens, teoria sempre aberta. Que outros arte/educadores elaborem suas interpretações, retomando e reabrindo a Abordagem Triangular.

\section{Referências}

AZEVEDO, Fernando. A arte possibilita ao ser humano repensar suas certezas e reinventar seu cotidiano. In: BARBOSA, Ana Mae; COUTINHO, Rejane Galvão (Org.). Arte/educação como mediação cultural e social. São Paulo: UNESP, 2009.

AZEVEDO, Fernando; ARAÚJO, Clarissa Martins de. Abordagem Triangular: leitura de imagens de diferentes códigos estéticos e culturais. Revista GEARTE, Porto Alegre, v. 2, n. 3, p. 345-358, set./dez. 2015. Disponível em: <http://seer.ufrgs.br/index.php/gearte/article/view/53833/36216>. Acesso em: 20 fev. 2017.

BARBOSA, Ana Mae. Toda Beleza na TV. In: Encontro Nacional da Associação Nacional de Pesquisadores em Artes Plásticas, 16, 2017. Florianópolis. Anais... Editora da UDESC, 2017. p. 660664. Disponível em: <http://anpap.org.br/anais/2007/2007/artigos/066.pdf>. Acesso em: 20 fev. 2017.

BARBOSA, Ana Mae. A imagem no ensino da arte: anos oitenta e novos tempos. São Paulo: Perspectiva; Porto Alegre: IOCHPE, 1991.

BARBOSA, Ana Mae. Tópicos utópicos. Belo Horizonte: C/Arte, 1998.

BENJAMIN, Walter. A obra de arte na era de sua reprodutibilidade técnica. In: BENJAMIN, Walter. Obras escolhidas. São Paulo: Brasiliense, 1996. 
BOURDIEU, Pierre. A distinção: crítica social do julgamento. São Paulo: Edusp; Porto Alegre: Zouk, 2007.

BOURRIAUD, Nicolas. Pós-Produção: como a arte reprograma o mundo contemporâneo. São Paulo: Martins Fontes, 2009.

EFLAND, Arthur. Cultura, sociedade e educação num mundo pós-moderno. In: BARBOSA, Ana Mae; GUINSBURG, Jacob (Org.). O pós-modernismo. São Paulo: Perspectiva, 2005

FREIRE, Paulo. Pedagogia do oprimido. São Paulo: Paz e Terra, 2005

GADOTTI, Moacir. Paulo Freire: uma biobibliografia. São Paulo: Cortez; Instituto Paulo Freire; Brasília: UNESCO, 1996.

LARROSA, Jorge. Pedagogia profana: danças, piruetas e mascaradas. Belo Horizonte: Autêntica, 2015.

MELLO, Luiz Carlos. Nise da Silveira: caminhos de uma psiquiatra rebelde. Rio de Janeiro: Automática; Hólos Consultores Associados, 2015.

NIETZSCHE, Friedrich. Humano, demasiado humano. São Paulo: Companhia das Letras, 2005.

ORLANDI, Eni. A materialidade do gesto de interpretação e o discurso eletrônico. In. DIAS, Cristiane. Formas de mobilidade no espaço e-urbano: sentido e materialidade digital [on-line]. Série e-urbano. v. 2, 2013. Consultada no Portal Labeurb - http://www.labeurb.unicamp.br/livroEurbano/ Laboratório de Estudos Urbanos - LABEURB/Núcleo de Desenvolvimento da Criatividade - NUDECRI, Universidade Estadual de Campinas - UNICAMP.

ORLANDI, Eni. Autoria, leitura e efeitos do trabalho simbólico. Campinas: Pontes, 2007.

ORLANDI, Eni. Análise de discurso: sujeito, sentido e ideologia. Campinas: Pontes, 2012.

PILLAR, Analice Dutra. Apontamentos para leitura de desenhos animados e videoartes. In: Encontro Nacional de Pesquisadores em Artes Plásticas, 20, 2011. Rio de Janeiro. Anais... UFRJ, 2011. p. 295309. Disponível em: <http://anpap.org.br/anais/2011/pdf/ceav/analice_dutra_pillar.pdf>. Acesso em: 2 mar. 2017.

ROSA, João Guimarães. Grande Sertão: veredas. São Paulo: Martins Fontes, 2006.

SANTOS, Boaventura. Um discurso sobre as ciências. Porto: Afrontamento, 2010.

SANTOS, Boaventura. A incerteza entre o medo e a esperança. In: Bienal de São Paulo, 32, 2016, São Paulo. Catálogo da 32ª Bienal de São Paulo. São Paulo: Fundação Bienal de São Paulo, 2016. p. 3745. Disponível em: <http://www.bienal.org.br/publicacao.php?i=3325>. Acesso em: 2 de mar. 2017.

VOLZ, Jochen. Jornadas Espirais: Incerteza Viva. In: Bienal de São Paulo, 32, 2016, São Paulo. Catálogo da 32a Bienal de São Paulo. São Paulo: Fundação Bienal de São Paulo, 2016. p. 21-27. Disponível em: <http://www.bienal.org.br/publicacao.php?i=3325>. Acesso em: 2 de mar. 2017.

\section{Fernando Antônio Gonçalves de Azevedo}

Doutor em Educação pela Universidade Federal de Pernambuco (UFPE), mestre em Artes pela Universidade de São Paulo (USP), especialista em Ensino da Arte pela Universidade Federal do Rio Grande do Norte (UFRN), especialista em Artes Cênicas pela UFPE e graduado em Filosofia pela Universidade Católica de Pernambuco (UNICAP). Professor do curso de Pedagogia na Unidade Acadêmica de Garanhuns da Universidade Federal Rural de Pernambuco (UFRPE/UAG). Participa do Grupo de Pesquisa em Educação e Arte - GEARTE, DGP/CNPq - e do Grupo de Pesquisa Formação de Professores, Arte e Inclusão - GEFAI, DGP/CNPq.

E-mail: f_azevedo@hotmail.com

Currículo: http://lattes.cnpq.br/6665135954352936

Recebido em 13 de março de 2017 Aceito em 18 de maio de 2017 